\title{
Antibiotic Prophylaxis Improves Ureaplasma-Associated Lung Disease in Suckling Mice
}

\author{
SCOTT A. WALLS, LINGKUN KONG, HEDDA A. LEEMING, FRANK X. PLACENCIA, EDWINA J. POPEK, \\ AND LEONARD E. WEISMAN
}

\author{
Departments of Pediatrics [S.A.W., L.K., H.A.L., F.X.P., L.E.W.] and Pathology [E.J.P.], Baylor College of Medicine, Texas Children's \\ Hospital, Houston, Texas 77030
}

\begin{abstract}
Ureaplasma infection is associated with increased lung disease in high-risk neonates. Our goal was to determine the impact of antibiotic prophylaxis on Ureaplasma and oxygen-induced lung disease in newborn mice. In animal model development and prophylaxis experiments, pups were randomly assigned to either 0.8 or 0.21 inspired oxygen concentration [fraction of inspired oxygen $\left(\mathrm{FiO}_{2}\right)$ ] from 1 to $14 \mathrm{~d}$ of age and either Ureaplasma or $10 \mathrm{~B}$ media daily from 1 to $3 \mathrm{~d}$. All pups were observed for growth and survival. Surviving pups had culture and PCR evaluated for blood, bronchoalveolar lavage, and lung, and lung weights, pathology, morphometry, histology, and immunohistochemistry were determined. In prophylaxis experiments, erythromycin, azithromycin, or normal saline was given for the first $3 \mathrm{~d}$, and minimum inhibitory concentration and pharmacokinetics were determined. In model development, $0.8 \mathrm{FiO}_{2}$ and Ureaplasma infection survival and growth were significantly decreased and lung edema and inflammation were significantly increased. In prophylaxis experiments, we observed significantly improved survival and growth with azithromycin versus normal saline controls, whereas erythromycin was not significantly different from controls, and decreased inflammatory response with azithromycin versus normal saline and erythromycin. In a neonatal mouse model of Ureaplasma and oxygen-induced lung disease, appropriate antibiotic prophylaxis improves survival and morbidity and decreases lung inflammation. (Pediatr Res 66: 197-202, 2009)
\end{abstract}

$\mathrm{U}$ reaplasma, commonly isolated from the newborn lower respiratory tract (1-3), is insensitive to beta-lactam antibiotics (4). This organism can be found in the genital tract of pregnant women. Amniotic fluid or placenta infection with Ureaplasma is associated with preterm labor, prematurity, low birth weight, and fetal death $(1,2,5,6)$.

Premature infants with Ureaplasma infection have an increased incidence of pneumonia and bronchopulmonary dysplasia (BPD) $(1,5)$. Ureaplasma lung infection is associated with increased polymorphonuclear leukocytes in tracheal aspirates and focal loss of ciliated epithelium $(5,6)$ and is more likely to progress to dysplastic changes and chronic lung disease compared with pneumonia attributed to other bacteria (4).

Received December 1, 2008; accepted April 10, 2009

Correspondence: Leonard E. Weisman, M.D., Department of Pediatrics, Baylor College of Medicine, 6621 Fannin (MC FC830.17), Houston, TX 77030; e-mail: lweisman@bcm.edu

Supported by the Section of Neonatology and Department of Pediatrics at Baylor College of Medicine, Houston, TX.

Presented as an abstract at the Pediatric Academic Societies Meeting, Honolulu, Hawaii, May 3, 2008 and XXI European Congress of Perinatal Medicine, Istanbul, Turkey, September 12, 2008.
Erythromycin has been used to treat or prevent Ureaplas$m a$-associated lung disease due to unacceptable side effects of other potential agents $(7,8)$. A Cochrane review of 17 studies evaluating erythromycin for the prevention of chronic lung disease found no decrease in BPD incidence or severity (8). In another study, erythromycin failed to eradicate colonization or infection in up to $50 \%$ of patients (7). However, these studies did not evaluate organism antibiotic sensitivity or antibiotic kinetics. In addition, the effectiveness of antibiotic prophylaxis or treatment in an animal model of Ureaplasmaassociated lung disease has not been evaluated. Thus, we developed a neonatal mouse model of Ureaplasma-associated lung disease and investigated the effectiveness of antibiotic prophylaxis in reducing mortality and morbidity.

\section{METHODS}

Organism. A clinical Ureaplasma strain (serotype 14, Ureaplasma parvum) isolated from a 25 -wk gestation placenta was diluted $1 / 100$ with $10 \mathrm{~B}$ broth (Remel Inc., Lenexa, KS) and grown before each use from a frozen stock solution $\left(5 \times 10^{6}\right.$ color changing units $\left./ \mathrm{mL}\right)$. The $U$. parvum species was selected because it is most commonly isolated from clinical specimens (2). Twenty microliters of the resultant solution was added to $50 \mathrm{~mL}$ of $10 \mathrm{~B}$ broth and grown for $16 \mathrm{~h}$ at $32.5^{\circ} \mathrm{C}$, centrifuged at $3000 \mathrm{rpm}$ for $30 \mathrm{~min}$, and the pellets resuspended in $900 \mu \mathrm{L}$ of 10B. This final solution used for infection had a concentration of $5 \times 10^{6}$ color changing units $/ \mathrm{mL}$.

Animals. FVB albino mice (Charles River Laboratories Inc., Wilmington, MA) were time impregnated and fed antibiotic free water and food ad libitum. Pups were kept with dams throughout each experiment. At $14 \mathrm{~d}$, surviving pups were euthanized with injection of $2.25-4.5 \mathrm{~mL} / \mathrm{kg}$ of $20 \%$ Rodent Comboanesthetic III (ketamine $37.6 \mathrm{mg} / \mathrm{mL}$, xylazine $1.92 \mathrm{mg} / \mathrm{mL}$, and acepromazine $0.38 \mathrm{mg} / \mathrm{mL}$ ). The Institutional Animal Use Committee approved the experiments.

Minimum inhibitory concentration and minimum bactericidal concentration. A microdilution method was performed as described previously to determine the minimum inhibitory concentration (MIC) and minimum bactericidal concentration (MBC) (9). Culture confirmation was performed on an A7 Agar plate (9).

Animal model. One-day-old littermates randomly received either 0.21 or 0.8 inspired oxygen concentration [fraction of inspired oxygen $\left(\mathrm{FiO}_{2}\right)$ ] $(10,11)$. Four hours later, pups randomly received either Ureaplasma or 10B broth (see Organism section above) intramuscularly as follows: $0.1 \mathrm{~mL}$ on d $1,0.2 \mathrm{~mL}$ on $\mathrm{d} 2$, and $0.3 \mathrm{~mL}$ on d 3 . Dams were alternated every $24 \mathrm{~h}$ between 0.21 and $0.8 \mathrm{FiO}_{2}$. A $0.8-\mathrm{FiO}_{2}$ environment resulted from mixing compressed air and oxygen (Bird low flow oxygen blender, Palm Springs, $\mathrm{CA}$ ) in a Plexiglas chamber. Carbon dioxide was collected using soda lime (indicating type, 4-8 mesh; Mallinckrodt Baker, Phillipsburg, NJ). Oxygen concentration was monitored daily with an oximeter (Hudson Ventronics

\footnotetext{
Abbreviations: BAL, bronchoalveolar lavage; BPD, bronchopulmonary dysplasia; $\mathbf{F i O}_{2}$, inspired oxygen concentration; $\mathbf{M B C}$, minimum bactericidal concentration; MIC, minimum inhibitory concentration
} 
5590, Temecula, CA). Pups were evaluated daily for survival and growth for $14 \mathrm{~d}$, then euthanized (see Animal section above), and randomly evaluated for lung weight analysis; Ureaplasma culture and PCR of blood, homogenized lung, and bronchoalveolar lavage (BAL); and lung tissue histology, inflammation, and morphometry.

Lung weight analysis. Whole lungs were obtained via blunt dissection, weighed immediately, and reweighed after air drying. Final lung dry weight was obtained after consecutive days without weight loss. Lung wet/dry ratio and wet lung/body weight ratio were documented as an index of lung injury (12).

Ureaplasma cultures. Hundred microliters of blood was obtained via cardiac puncture from each pup.

Lungs were perfused intratracheally with $0.5 \mathrm{~mL}$ of a 1:1 mixture of $99 \%$ glycerin (Sigma-Aldrich, St. Louis, MO) and normal saline through a 21gauge needle on a 3-mL syringe and the BAL sample obtained with suction applied after instillation of the mixture (13).

Lung tissue was homogenized between a $60 \times 15 \mathrm{~mm}$ petri culture dish (Pyrex, Lowell, MA) and a 4-mL glass vial (Kimble Glass Inc., Raleigh, NC) in a sterile fashion (10).

The culture samples (blood, BAL, lung homogenate) were placed in 700 $\mu \mathrm{L}$ of $10 \mathrm{~B}$ broth and incubated (Precision Scientific Group, Chicago, IL) at $37^{\circ} \mathrm{C}$. Samples were examined daily for $2 \mathrm{wk}$ for color change and cultures confirmed on A7 Agar (14).

Ureaplasma PCR. All culture (blood, BAL, lung homogenate) samples were prepared for PCR by vortexing briefly before centrifuging at $1000 \mathrm{rpm}$ for $10 \mathrm{~s}$ (Beckman Coulter, Fullerton, CA). The supernatant was centrifuged at $1000 \mathrm{rpm}$ for $20 \mathrm{~min}$ and pellets were lysed with $20 \mathrm{mM}$ Tris- $\mathrm{HCl}, 50 \mathrm{mM}$ $\mathrm{KCl}, 2.5 \mathrm{mM} \mathrm{MgCl}$, and $0.5 \%$ Tween 20 . Proteinase $\mathrm{K}(300 \mu \mathrm{g} / \mathrm{mL}$; Qiagen, Valencia, CA) was added before 2-h incubation at $60^{\circ} \mathrm{C}$, followed by $10 \mathrm{~min}$ at $94^{\circ} \mathrm{C}$. PCR was performed using primers directed toward the urease genes specific for Ureaplasma: primers U4a (antisense primer, 5'-acg acg tcc ata agc aac aac t- $3^{\prime}$ ) and U5s (sense primer, $5^{\prime}$-caa tct gct cgt gaa gta tta c- $3^{\prime}$ ). The reaction mixture was subjected to the following thermal cycling parameters in a PTC-200 model Peltier Thermal Cycler (MJ Research, Waltham, MA): 34 cycles of $30 \mathrm{~s}$ at $94^{\circ} \mathrm{C}, 60 \mathrm{~s}$ at $60^{\circ} \mathrm{C}, 60 \mathrm{~s}$ at $72^{\circ} \mathrm{C}$, and then $10 \mathrm{~min}$ at $72^{\circ} \mathrm{C}$. The PCR product was stored at $4^{\circ} \mathrm{C}$ and run on $2 \%$ agarose gel. Positive and negative DNA controls, and water controls were processed in parallel to detect false negatives and contamination (2). Each assay had a detection limit of approximately five copies per reaction of the respective gene target.

Lung pathology. Lung tissue was formalin fixed, paraffin embedded, and sectioned at $4 \mu \mathrm{m}$ after intratracheal instillation of $10 \%$ zinc formalin at constant pressure (12). Fixative was introduced via a transtracheal needle into the lung in situ. The trachea tied off to retain the fixative at the filling pressure. Lungs were visualized as they were inflated to ensure no overinflation. The filling pressure used for inflation was a constant $4 \mathrm{~cm} \mathrm{H}_{2} \mathrm{O}$. Fixed lungs were stained with hematoxylin and eosin and anti-neutrophil antibody (AbD Serotec, Oxford, United Kingdom) (15). Anti-neutrophil antibody-stained tissue was used to count neutrophils at $\times 40$ in five high-power fields/pup. Hematoxylin and eosin-stained tissue was used to evaluate morphology and inflammation. Lung morphometry was documented by measuring the volume in alveolar space at $\times 40$ in 40 high-power fields/pup using BioQuant Life Science software (BioQuant Image Analysis Corporation, Nashville, TN). All samples were evaluated by a pathologist in a blinded fashion.

Antibiotics. Erythromycin (USP, Rockville, MD) was selected based on historical data and practice $(1,6,8)$ and azithromycin (Baxter, Deerfield, IL) on current and local data (Ref. 16 and Oluola $\mathrm{O}$ et al., Ureaplasma colonization of the placenta and preterm birth, 2007 Pediatric Academic Society Annual Meeting, May 5, 2007, Toronto, Canada, Abstract 615906.3). Antibiotic dose and frequency were based on clinical guidelines $(1,6,8,16)$. Antibiotic powders were dissolved with normal saline per manufacturer recommendation. Fresh stock solutions were prepared daily.

Pharmacokinetics. One-day-old pups received either intraperitoneal erythromycin $20 \mathrm{mg} / \mathrm{kg} /$ dose twice a day for $3 \mathrm{~d}$ or azithromycin $12 \mathrm{mg} / \mathrm{kg} / \mathrm{dose}$ daily for $3 \mathrm{~d}$. Blood was collected by cardiac puncture at 1, 5, 7, 23, 25, 29, $31,47,49,53,55,72$, and $96 \mathrm{~h}$. Blood from two to three pups was pooled per data point, and two data points were obtained for each time point.

Drug level assays. Antibiotic levels were obtained by bioassay (17). Standard dilutions of erythromycin and azithromycin were prepared $(17,18)$. Agar plates were inoculated with Kocuria rhizophila (ATCC 9341). Reference and unknown wells were filled, zones of inhibition read, and values obtained from a standard curve (17).

Prevention model. As above, one-day-old pups were placed in 0.21 or 0.8 $\mathrm{FiO}_{2}$ (Animal Model), $2 \mathrm{~h}$ later prophylaxis began with erythromycin, azithromycin, or normal saline (Pharmacokinetics), and $2 \mathrm{~h}$ later they received either Ureaplasma or 10B and were evaluated (Animal Model).

Statistical analysis. Survival data were analyzed by $\chi^{2}$ or Fisher exact test and cultures by Kruskal-Wallis. Growth curves were constructed for individ- ual pups (even those who died in the study period), slopes calculated, and means of the slopes for each group compared by one-way ANOVA. One-way ANOVA with Dunnett's multiple comparison tests were performed to analyze lung wet/dry weight and wet lung/body weight ratios. $t$ test was used to evaluate anti-neutrophil antibody counts. Results are expressed as mean \pm SEM. The sample size estimate of $>65$ mouse pups per group was based on an untreated survival of $50 \%$, a treated survival of $75 \%, p$ value of $\leq 0.05$, power of 0.8 , and a two-sided comparison. A $p$ value $\leq 0.05$ was considered statistically significant for all calculations. MINITAB Release 13.3 (State College, PA) and GraphPad Prism 4 were used for analysis (GraphPad Software, Inc., San Diego, CA).

\section{RESULTS}

Model survival. Figure 1 illustrates the survival of suckling mice in the animal model. Pups exposed to $0.8 \mathrm{FiO}_{2}$ and infected with Ureaplasma had a survival rate of $63 \%(n=70)$, whereas pups exposed to $0.8 \mathrm{FiO}_{2}$ alone or $0.21 \mathrm{FiO}_{2}$ alone had a survival rate of $99 \%$ ( $n=71$ and $n=72$, respectively). Pups exposed to Ureaplasma alone had a survival rate of $96 \%$ $(n=67)$. The difference between the hyperoxia-exposed and Ureaplasma-infected group versus each of the other groups was statistically significant $(p<0.00001)$.

Model growth. The $0.8 \mathrm{FiO}_{2}$ and Ureaplasma-infection group had a weight gain of $0.275 \mathrm{~g} / \mathrm{d}( \pm 0.044, n=70)$. This rate of weight gain was significantly different from that in the other groups $(p \leq 0.01)$, which were $0.385 \mathrm{~g} / \mathrm{d}( \pm 0.007, n=$ 67) for $0.21 \mathrm{FiO}_{2}$ and Ureaplasma-infection group; $0.391 \mathrm{~g} / \mathrm{d}$ $( \pm 0.008, n=71)$ for $0.8 \mathrm{FiO}_{2}$ and $10 \mathrm{~B}$ broth group; and $0.380 \mathrm{~g} / \mathrm{d}( \pm 0.009, n=72)$ for $0.21 \mathrm{FiO}_{2}$ and $10 \mathrm{~B}$ broth group.

Model lung ratios. The lung wet/dry weight ratio in the model pups exposed to $0.8 \mathrm{FiO}_{2}$ and Ureaplasma infection had a ratio of $8.86( \pm 3.03, n=15)$ compared with the 0.21 $\mathrm{FiO}_{2}$ and Ureaplasma-infection group ratio of $4.77( \pm 0.29$, $n=44$ ), the $0.8 \mathrm{FiO}_{2}$ and $10 \mathrm{~B}$ broth group ratio of 6.30 $( \pm 1.99, n=39)$, and the $0.21 \mathrm{FiO}_{2}$ and $10 \mathrm{~B}$ broth group ratio of $4.13( \pm 0.39, n=56)$. The $0.8 \mathrm{FiO}_{2}$ and Ureaplasmainfection group had a significantly different lung wet/dry ratio compared with the $0.21 \mathrm{FiO}_{2}$ and Ureaplasma-infection group $(p \leq 0.05)$ and the $0.21 \mathrm{FiO}_{2}$ and 10B broth group $(p \leq 0.01)$, but not the $0.8 \mathrm{FiO}_{2}$ and $10 \mathrm{~B}$ broth group.

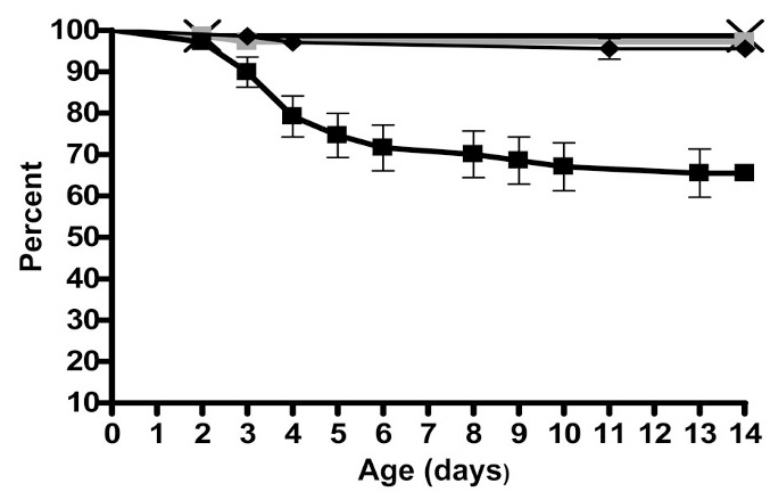

Figure 1. Model survival. Survival of suckling mice over time in days after assignment to model group. Rectangles, $0.8 \mathrm{FiO}_{2}$ and Ureaplasma infection, $n=70(63 \%)$; diamonds, $0.21 \mathrm{FiO}_{2}$ and Ureaplasma infection, $n=67(96 \%)$; gray square, $0.8 \mathrm{FiO}_{2}$ and $10 \mathrm{~B}$ broth, $n=71(99 \%)$; and $X, 0.21 \mathrm{FiO}_{2}$ and $10 \mathrm{~B}$ broth, $n=72(99 \%)$. Survival was significantly decreased in the $0.8 \mathrm{FiO}_{2}$ and Ureaplasma-infected group $(p \leq 0.00001) v s$ every other group. Data expressed as mean \pm SEM. 
The wet lung/body weight ratio data of pups exposed to 0.8 $\mathrm{FiO}_{2}$ and Ureaplasma infection had a ratio of $0.018( \pm 0.001$, $n=15)$ compared with the $0.21 \mathrm{FiO}_{2}$ and Ureaplasmainfection group ratio of $0.14( \pm 0.001, n=44)$, the $0.8 \mathrm{FiO}_{2}$ and 10B broth group ratio of $0.013( \pm 0.001, n=41)$, and the $0.21 \mathrm{FiO}_{2}$ and $10 \mathrm{~B}$ broth group ratio of $0.013( \pm 0.001, n=61)$. The difference between the $0.8 \mathrm{FiO}_{2}$ exposed and Ureaplasmainfected group versus each of the other groups was statistically significant $(p \leq 0.01)$.

Model cultures. Cultures were obtained in surviving pups at $14 \mathrm{~d}$ to evaluate the pervasiveness of Ureaplasma in the animal model. Blood cultures and PCR $\left(0.21 \mathrm{FiO}_{2}\right.$ and Ureaplasma, $n=25 ; 0.8 \mathrm{FiO}_{2}$ and Ureaplasma, $n=16$ ), $\mathrm{BAL}$ cultures $\left(0.21 \mathrm{FiO}_{2}\right.$ and Ureaplasma, $n=11 ; 0.8 \mathrm{FiO}_{2}$ and Ureaplasma, $n=14)$, and homogenized lung culture $(0.21$ $\mathrm{FiO}_{2}$ and Ureaplasma, $n=15 ; 0.8 \mathrm{FiO}_{2}$ and Ureaplasma, $n=$ $13)$ were all negative. The BAL PCR was positive in only $18 \%$ ( 2 of 11 ) and $29 \%$ ( 4 of 14) of the pups exposed to $0.21 \mathrm{FiO}_{2}$ and Ureaplasma and $0.8 \mathrm{FiO}_{2}$ and Ureaplasma, respectively. The homogenized lung PCR was negative in the entire 0.21 $\mathrm{FiO}_{2}$ and Ureaplasma group $(n=15)$ and positive in $15 \%(2$ of 13) of the $0.8 \mathrm{FiO}_{2}$ and Ureaplasma group. The numbers were small, and there was no statistical difference between Ureaplasma-infected groups. Before this study, 10 pups in the $0.8 \mathrm{FiO}_{2}$ and Ureaplasma group were euthanized and lungs cultured $6 \mathrm{~h}$ after the last dose of Ureaplasma on d 3, and all had Ureaplasma in their lung confirmed by culture and PCR.

Model lung histopathology. Infection with Ureaplasma or exposure to oxygen, or both, resulted in significant inflammation compared with nonexposed controls. Infection with Ureaplasma and exposure to oxygen appear to demonstrate increased inflammation compared with either one alone (see Figs. $2 A, B$ and $3 A, B)$. Lung tissue anti-neutrophil antibody staining found neutrophil counts of $111.4( \pm 15, n=7)$ for $0.8 \mathrm{FiO}_{2}$ and Ureaplasma group, compared with the $0.21 \mathrm{FiO}_{2}$ and Ureaplasma group $71.3( \pm 10.6, n=7)$ and the $0.8 \mathrm{FiO}_{2}$ and 10B broth group $67( \pm 7, n=7)$. The $0.8 \mathrm{FiO}_{2}$ and Ureaplas$m a$-infection group had significantly increased lung neutrophil counts compared with the $0.21 \mathrm{FiO}_{2}$ and Ureaplasmainfection group $(p=0.049)$ and the $0.8 \mathrm{FiO}_{2}$ and $10 \mathrm{~B}$ broth group $(p=0.025)$. There was no statistically significant difference among the groups in lung morphometry (data not

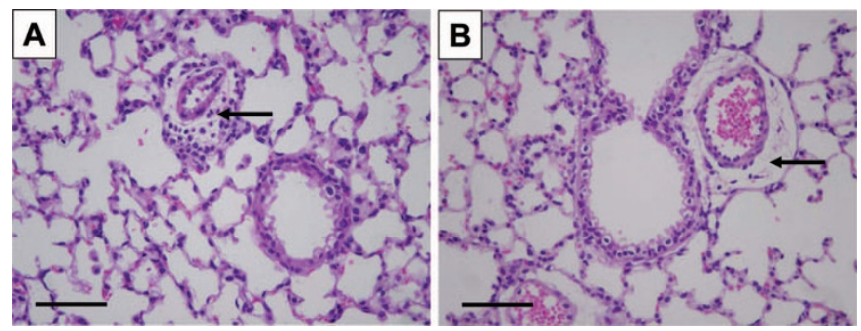

Figure 2. A, Histopathologic appearance of hematoxylin and eosinstained lung from $0.8 \mathrm{FiO}_{2}$ and Ureaplasma-infection group at $14 \mathrm{~d}$ of age $(\times 20)$. Arrow points to neutrophils in perivascular space. Bar length in lower left had corner equals $100 \mu \mathrm{m}$. B. Histopathologic appearance of hematoxylin and eosin-stained lung from $0.21 \mathrm{FiO}_{2}$ and Ureaplasmainfection group at $14 \mathrm{~d}$ of age $(\times 20)$. Arrow points to absence of neutrophils in perivascular space. Bar length in lower left had corner equals $100 \mu \mathrm{m}$.

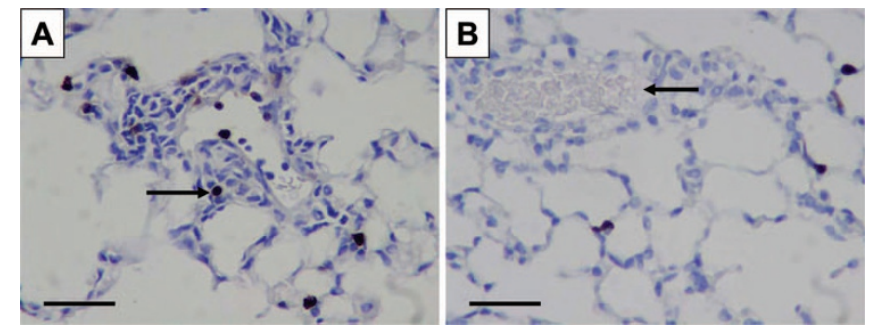

Figure 3. $A$, Histologic appearance of anti-neutrophil antibody-stained lung from $0.8 \mathrm{FiO}_{2}$ and Ureaplasma-infection group at $14 \mathrm{~d}$ of age $(\times 40)$. Arrow points to neutrophils in perivascular space. Bar length in lower left had corner equals $50 \mu \mathrm{m}$. $B$, Histologic appearance of anti-neutrophil antibody-stained lung from $0.21 \mathrm{FiO}_{2}$ and Ureaplasma-infection group at $14 \mathrm{~d}$ of age $(\times 40)$. Arrow points to absence of neutrophils in perivascular space. Bar length in lower left had corner equals $50 \mu \mathrm{m}$.

shown). Before this study, 10 pups in the $0.8 \mathrm{FiO}_{2}$ and Ureaplasma group and 10 normal pups not exposed to oxygen or infected were euthanized at $3 \mathrm{~d}$ and autopsies performed. The findings in the oxygen exposed and infected pups included the consistent presence of hyaline membranes with occasional fibrin, blood, edema, and large alveoli. The histopathology of the interstitium, perivascular space, and peribronchial space was unremarkable.

Ureaplasma $M I C / M B C$. For this strain of Ureaplasma, the $\mathrm{MIC}$ and $\mathrm{MBC}$ for erythromycin and azithromycin were 62.5 $\mu \mathrm{g} / \mathrm{mL}$ and $0.25 \mu \mathrm{g} / \mathrm{mL}$, respectively.

Pharmacokinetics. Erythromycin serum levels never achieved concentrations necessary for MIC (see Fig. 4). Only azithromycin peak serum levels achieved concentrations necessary for MIC (see Fig. 5).

Prophylaxis survival. The survival rate of pups that received azithromycin prophylaxis $(68 \%)$ was statistically significant $(p \leq 0.042)$ compared with pups that received normal saline (53\%; Fig. 6). Survival after erythromycin prophylaxis $(56 \%)$ was not significantly different from normal saline $(53 \% ; p=0.87)$. Azithromycin prophylaxis $(68 \%)$ was not statistically different from erythromycin prophylaxis (56\%; $p=0.17$ ).

Prophylaxis growth. The growth rate of pups was $0.38 \mathrm{~g} / \mathrm{d}$ $( \pm 0.017, n=75)$ for azithromycin prophylaxis, 0.34 $\mathrm{g} / \mathrm{d}( \pm 0.019, n=75)$ for erythromycin prophylaxis, and 0.33

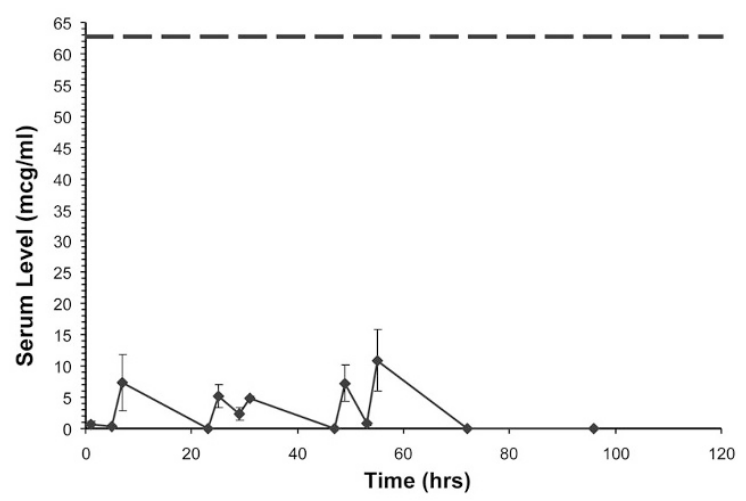

Figure 4. Erythromycin serum concentrations vs time in hours in the neonatal mouse. MIC of Ureaplasma clinical strain represented by dashed line $(62.5 \mu \mathrm{g} / \mathrm{mL})$. Serum levels expressed as mean \pm SEM. 


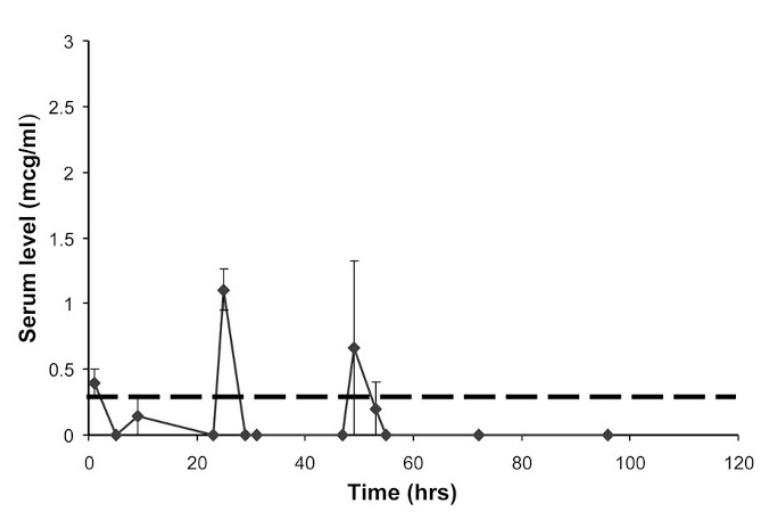

Figure 5. Azithromycin concentrations $v s$ time in hours in the suckling mouse. MIC of Ureaplasma clinical strain represented by dashed line $(0.25$ $\mu \mathrm{g} / \mathrm{mL})$. Serum levels expressed as mean \pm SEM.

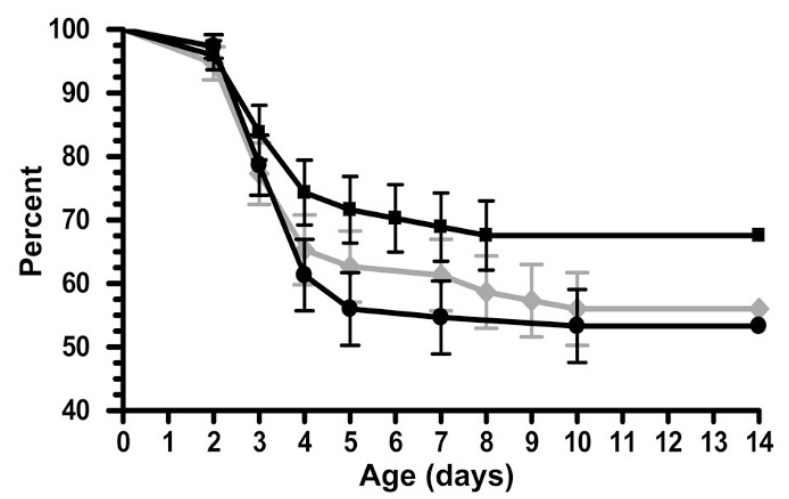

Figure 6. Prophylaxis survival. Survival of suckling mice over time in days after assignment to prophylaxis group. Circle, $0.8 \mathrm{FiO}_{2} /$ normal saline/Ureaplasma infection, $n=75$ (53\%); gray diamond, $0.8 \mathrm{FiO}_{2} /$ erythromycin/Ureaplasma infection, $n=75$ (56\%); square, $0.8 \mathrm{FiO}_{2} /$ azithromycin/Ureaplasma infection, $n=75(68 \%)$. Survival was significantly improved in the azithromycin $v s$ normal saline ( $p \leq 0.042)$, but not in the azithromycin $v s$ erythromycin $(p=0.17)$ and erythromycin $v s$ normal saline $(p=0.87)$ groups. Data expressed as mean \pm SEM.

$\mathrm{g} / \mathrm{d}( \pm 0.016, n=75)$ for normal saline controls. The growth rate of pups who received azithromycin prophylaxis was significantly greater than that of pups who received normal saline $(p \leq 0.05)$. There was no statistical difference in the growth rate between azithromycin and erythromycin prophylaxis $(p>0.05)$ or erythromycin and normal saline prophylaxis $(p>0.05)$.

Prophylaxis lung ratios. There were no statistically significant differences in lung ratios between erythromycin and azithromycin prophylaxis groups including lung wet/dry weight ratio or wet lung/body weight ratio (data not shown).

Prophylaxis cultures. In the prophylaxis experiment, the results of blood cultures and blood PCR (erythromycin, $n=$ 19; azithromycin, $n=18$; normal saline, $n=15$ ), BAL culture (erythromycin, $n=12$; azithromycin, $n=17$; normal saline, $n=15$ ), and homogenized lung culture (erythromycin, $n=5$; azithromycin, $n=6$; normal saline, $n=5$ ) were all negative. BAL PCR was positive in $25 \%$ (3 of 12) of erythromycin, and 24\% (4 of 17) of azithromycin pups. Homogenized lung PCR were positive in 40\% (2 of 5) of erythromycin and $33 \%$ ( 2 of 6 ) of azithromycin animals. The numbers were small, and there was no significant difference between the groups.
Prophylaxis lung histopathology. There was no statistical difference in lung morphometry between erythromycin and azithromycin prophylaxis groups (data not shown). However, azithromycin prophylaxis resulted in significantly less inflammation based on lower neutrophil counts than normal saline $(p=0.017)$ or erythromycin $(p=0.039)$. Anti-neutrophil antibody staining data for normal saline controls were 92.9 $( \pm 7.5, n=7)$, compared with the erythromycin prophylaxis group count of $90.9( \pm 9.7, n=7)$ and the azithromycin prophylaxis group count of $59.3( \pm 9.4 .1, n=7)$.

\section{DISCUSSION}

This study revealed that mouse pups exposed to oxygen and Ureaplasma had significantly increased mortality, decreased growth rate, increased lung injury, and increased inflammation compared with pups exposed to Ureaplasma, oxygen, or room air alone. This correlates with previous clinical studies that independently link Ureaplasma with BPD (19-22) and death (22) despite surfactant treatment (21), and more recent studies and reviews continue to support this link (23-25). These studies showed differences in the studied populations, entrance criteria, and study design. However, the risks of developing chronic lung disease in infants colonized with Ureaplasma were similar in all studies.

The possible mechanisms for Ureaplasma and hyperoxia interaction that result in increased BPD have not been definitively determined. Hyperoxia may serve as a cofactor for Ureaplasma pulmonary dissemination similar to Pseudomonas (26) or cause persistence of Ureaplasma in the lung (27). In either case, the combination of hyperoxia and Ureaplasma appears to potentiate the pulmonary cellular inflammatory response (27) and/or proinflammatory cytokine response $(28,29)$. Azithromycin treatment may limit the dissemination (26) or persistence of Ureaplasma in the lung or directly suppress the inflammatory response to hyperoxia (30) or Ureaplasma, or both. Our results suggest that azithromycin treatment appears to suppress the overall Ureaplasma infection and inflammatory response of Ureaplasma and oxygeninduced lung disease. Additional work is needed to determine a precise mechanism.

There are few newborn mouse models of Ureaplasmaassociated lung disease, and their methods are different from those in this experiment $(13,14,27)$. Previous models used intranasal or intratracheal administration to the organism. We selected intramuscular injection to ensure each animal was infected and not just colonized. The precise mechanism of infection in the human neonate or animal model, via airway or systemic circulation, is not known. A recent report observed $17.3 \%$ of 23- to 32-wk gestation infants had cord blood culture positive for Ureaplasma, suggesting a potential source for systemic infection (31). We measured survival, growth, blood cultures, lung and BAL cultures, lung edema, morphometry, histology, and inflammation, whereas prior studies only evaluated lung culture, histology, inflammation, and BAL culture, histology, and cytokines. Antibiotic prevention or treatment in these mouse models or in any animal model of Ureaplasmaassociated lung disease has not been evaluated. We selected 
prophylaxis because colonization has been reported at or shortly after birth (1). In addition, previous intervention strategies may have failed because treatment was delayed until cultures confirmed infection (8).

Pup growth was significantly decreased with Ureaplasma infection and hyperoxia. This growth reduction is similar to what is seen in animal models and neonates with BPD $(11,32)$. We also found that prophylaxis with azithromycin improved growth and survival compared with normal saline controls and erythromycin although the latter was not statistically significant.

Azithromycin may not have been statistically different from erythromycin in prophylaxis survival, growth, and hematoxylin and eosin stain, but lung inflammation was significantly less as measured by anti-neutrophil antibody staining. Differences between the erythromycin and azithromycin groups may have been minimized in part to the macrolide antiinflammatory properties $(30,33)$ or inadequate dosing of azithromycin. Future investigations should consider increased dosing regimens.

The decrease in lung inflammation with azithromycin compared with erythromycin may reflect the more specific isolation of neutrophils compared with the broad visualization of inflammation using hematoxylin and eosin staining. Although Viscardi et al. (13) report on some BAL cytokines and chemokines in their model, further investigation into the prophylaxis of Ureaplasma should consider evaluating systemic and airway inflammatory markers in this model.

Blood culture and PCR were all negative. This may be because Ureaplasma is an intracellular organism that is mucosally associated. Although cleared from the blood, Ureaplasma appears to target the lung and airway and may be delayed in clearance from the lung as demonstrated by persistence of Ureaplasma PCR in the lung of surviving pups. Prophylaxis did not alter the persistence of Ureaplasma in BAL or lung tissue. This appears similar to the human neonate, where Walsh et al. (34) reported that lung biopsy samples from infants were positive even though tracheal aspirates were negative.

Antibiotic pharmacokinetics in mice has not been evaluated. The pharmacokinetics of erythromycin and the MIC of the clinical Ureaplasma strain used in this experiment suggest that erythromycin would not be the drug of choice for prophylaxis. Ureaplasma strains have shown a variable sensitivity to antibiotics but azithromycin appears to be more effective in vitro than erythromycin (16). Azithromycin may be a more appropriate tool in the prophylaxis of Ureaplasma, because in a recent study, all clinical strains were sensitive to this antibiotic, whereas $83 \%$ were resistant to erythromycin (Oluola O et al., Ureaplasma colonization of the placenta and preterm birth, 2007 Pediatric Academic Society Annual Meeting, May 5, 2007, Toronto, Canada, Abstract 615906.3). Our serum antibiotic levels suggest that we may be using a less-thanadequate amount of azithromycin, however, serum levels of azithromycin may not reflect tissue levels. Azithromycin has been observed as having preferential distribution in lung tissue with increased macrophage uptake during infection (18). Fu- ture studies of this model should consider determining tissue levels.

The use and safety of azithromycin in the prophylaxis or treatment of Ureaplasma-associated lung disease in neonates warrants further investigation. In this prophylaxis model, where the host was infected with an organism that was resistant to erythromycin, azithromycin was an effective prevention strategy.

Acknowledgments. We thank Travis Markham for the initial work on the animal infection model and Dr. E. O'Brian Smith for his assistance in statistical calculations. We also thank Dr. Bhagavatula Moorthy for his assistance with the design of the experiments and review of the manuscript.

\section{REFERENCES}

1. Cassell GH, Waites KB, Watson HL, Crouse DT, Harasawa R 1993 Ureaplasma urealyticum intrauterine infection: role in prematurity and disease in newborns. Clin Microbiol Rev 6:69-87

2. Katz B, Patel P, Duffy L, Schelonka RL, Dimmitt RA, Waites KB 2005 Characterization of ureaplasmas isolated with and without bronchopulmonary dysplasia. J Clin Microbiol 43:4852-4854

3. Zheng X, Watson HL, Waites KB, Cassell GH 1992 Serotype diversity and antigen variation among invasive isolates of Ureaplasma urealyticum from neonates. Infect Immun 60:3472-3474

4. Pinna GS, Skevaki CL, Kafetzis DA 2006 The significance of Ureaplasma urealyticum as a pathogenic agent in the paediatric population. Curr Opin Infect Dis 19:283-289

5. Van Waarde WM, Brus F, Okken A, Kimpen JL 1997 Ureaplasma urealyticum colonization, prematurity and bronchopulmonary dysplasia. Eur Respir J 10:886890

6. Waites KB, Katz B, Schelonka RL 2005 Mycoplasmas and ureaplasmas as neonatal pathogens. Clin Microbiol Rev 18:757-789

7. Baier RJ, Loggins J, Kruger TE 2003 Failure of erythromycin to eliminate airway colonization with Ureaplasma urealyticum in very low birth weight infants. BMC Pediatr 3:10

8. Mabanta CG, Pryhuber GS, Weinberg GA, Phelps DL 2003 Erythromycin for the prevention of chronic lung disease in intubated preterm infants at risk for, or colonized or infected with Ureaplasma urealyticum. Cochrane Database of Syst Rev CD003744

9. Waites KB, Crabb DM, Bing X, Duffy LB 2003 In vitro susceptibilities to and bactericidal activities of Garenoxacin (BMS-284756) and other antimicrobial agents against human mycoplasmas and ureaplasmas. Antimicrob Agents Chemother 47:161-165

10. Barazzone C, Belin D, Piguet PF, Vassalli JD, Sappino A 1996 Plasminogen activator inhibitor-1 in acute hyperoxic mouse lung injury. J Clin Invest 98:26662673

11. Warner BB, Stuart LA, Papes RA, Wispé JR 1998 Functional and pathological effects of prolonged hyperoxia in neonatal mice. Am J Physiol 275:L110-L117

12. Jiang W, Welty SE, Couroucli XI, Barrios R, Kondraganti SR, Muthiah K, Yu L, Avery SE, Moorthy B 2004 Disruption of the Ah receptor gene alters the susceptibility of mice to oxygen-mediated regulation of pulmonary and hepatic cytochromes P4501A expression and exacerbates hyperoxic lung injury. J Pharmacol Exp Ther 310:512-519

13. Viscardi RM, Kaplan J, Lovchik JC, Ju RH, Hester L, Srinivas R, Hasday JD 2002 Characterization of a murine model of Ureaplasma urealyticum pneumonia. Infect Immun 70:5721-5729

14. Rudd PT, Cassell GH, Waites KB, Davis JK, Duffy LB 1989 Ureaplasma urealyticum pneumonia: experimental production and demonstration of age-related susceptibility. Infect Immun 57:918-925

15. Sinha A, Kathirvel M, Jiang W, Couroucli X, Barrios R, Moorthy B 2005 Attenuation of hyperoxic lung injury by the CYP1A inducer $\beta$-naphthoflavone. Toxicol Sci 87:204-212

16. Matlow A, Th'ng C, Kovach D, Quinn P, Dunn M, Wang E 1998 Susceptibilities of neonatal respiratory isolates of Ureaplasma urealyticum to antimicrobial agents. Antimicrob Agents Chemother 42:1290-1292

17. Bennett JV, Brodie JL, Benner EJ, Kirby WM 1966 Simplified, accurate method for antibiotic assay of clinical specimens. Appl Microbiol 14:170-177

18. Stamler DA, Edelstein MA, Edelstein PH 1994 Azithromycin pharmacokinetics and intracellular concentrations in Legionella pneumophilia infected and uninfected guinea pigs and their alveolar macrophages. Antimicrob Agents Chemother 38:217222

19. Sanchez PJ, Regan JA 1988 Ureaplasma urealyticum colonization and chronic lung disease in low birth weight infants. Pediatr Infect Dis J 7:542-546

20. Wang EE, Frayha H, Watts J, Hammerberg O, Chernesky MA, Mahony JB, Cassell GH 1988 The role of Ureaplasma urealyticum and other pathogens in the development of chronic lung disease of prematurity. Pediatr Infect Dis J 7:547-551 
21. Payne NR, Steinberg SS, Ackerman P, Chrenka BA, Sane SM, Anderson KT, Fangman JJ 1993 New prospective studies of the association of Ureaplasma urealyticum colonization and chronic lung disease. Clin Infect Dis 17:S117-S121

22. Cassell GH, Waites KB, Crouse DT, Rudd PT, Canupp KC, Stango S, Cutter GR 1988 Association of Ureaplasma urealyticum infection of the lower respiratory tract with chronic lung disease and death in very-low-birth-weight infants. Lancet 2:240245

23. Schelonka RL, Katz B, Waites KB, Benjamin DK Jr 2005 Critical appraisal of the role of Ureaplasma in the development of bronchopulmonary dysplasia with metaanalytic techniques. Pediatr Infect Dis J 24:1033-1039

24. Colaizy TT, Morris CD, Lapidus J, Sklar RS, Pillers DA 2007 Detection of Ureaplasma DNA in endotracheal samples is associated with bronchopulmonary dysplasia after adjustment for multiple risk factors. Pediatr Res 61:578-583

25. Viscardi RM, Hasday JD 2009 Role of Ureaplasma species in neonatal chronic lung disease: epidemiologic and experimental evidence. Pediatr Res (in press)

26. Kikuchi Y, Tateda K, Fuse ET, Matsumoto T, Gotoh N, Fukushima J, Takizawa H, Nagase T, Standiford TJ, Yamaguchi K 2009 Hyperoxia exaggerates bacterial dissemination and lethality in Pseudomonas aeruginosa pneumonia. Pulm Pharmacol Ther 22:333-339

27. Crouse DT, Cassell GH, Waites KB, Foster JM, Cassady G 1990 Hyperoxia potentiates Ureaplasma urealyticum pneumonia in newborn mice. Infect Immun $58: 3487-3493$
28. Manimtim WM, Hasday JD, Hester L, Fairchild KD, Lovchik JC, Viscardi RM 2001 Ureaplasma urealyticum modulates endotoxin-induced cytokine release by human monocytes derived from preterm and term newborns and adults. Infect Immun 69:3906-3915

29. Talati AJ, Crouse DT, English BK, Newman C, Livingston L, Meals E 1998 Exogenous bovine surfactant suppresses tumor necrosis factor-alpha release by murine macrophages stimulated by genital mycoplasmas. J Infect Dis 178:11221125

30. Ballard HO, Bernard P, Qualls J, Everson W, Shook LA 2007 Azithromycin protects against hyperoxic lung injury in neonatal rats. J Investig Med 55:299-305

31. Goldenberg RL, Andrews WW, Goepfert AR, Faye-Petersen O, Cliver SP, Carlo WA, Hauth JC 2008 The Alabama Preterm Birth Study: umbilical cord blood Ureaplasma urealyticum and Mycoplasma hominis cultures in very preterm newborn infants. Am J Obstet Gynecol 198:43.e1-43.e5

32. Jobe AH, Ikegami M 2001 Antenatal infection/inflammation and postnatal lung maturation and injury. Respir Res 2:27-32

33. Kudoh S 1998 Erythromycin treatment in diffuse panbronchiolitis. Curr Opin Pulm Med 4:116-121

34. Walsh WF, Stanky S, Lally KP, Stribley RE, Treece DP, McClesky F, Null DM 1991 Ureaplasma urealyticum demonstrated by open lung biopsy in newborns with chronic lung disease. Pediatr Infect Dis J 10:823-827 